\title{
Numerical Predication of Solidification Phenomena of Phase Change Material in Concentric Annulus Pipe
}

\author{
Balqies A. Abbas*, Mustafa B. Al-Hadithi \\ College of Engineering, Anbar University - Iraq
}

\section{Article information}

\section{Article history:}

Received: October, 07, 2021

Accepted: October, 28, 2021

Available online: December, 14, 2021

Keywords:

Solidification,

PCM,

CFD

*Corresponding Author:

Balqies A. Abbas

bal19e2007@uoanbar.edu.iq

DOI:

https://doi.org/10.53523/ijoirVol8I3ID98

\begin{abstract}
Two-dimensional numerical simulation is performed aiming to understand the role of buoyancy force convection during restricted solidification of phase change materials (PCMs) inside a shell and tube heat exchanger according to annulus cross section. Where the transient history of PCM solidification evolution was studied. The governing equations of mass, momentum and energy are solved to study the solidification behavior inside the annulus geometry. The fluid flow in the mushy zone was accounted for using the Darcy drag source term in momentum, and the liquid percentage in each cell was updated using the enthalpy-porosity method. Thermal conditions of the outer cylinder insulated (adiabatic) and the inner cylinder at constant temperature (isothermal). The results are presents as a temperature contour and liquid fraction distribution in the domain. The predicted result shows the capturing phenomenon: primary heat conduction in all regions, then heat convection and conduction become dominant in the top and bottom regions, respectively. The max. and min. temperature changes near the outer pipe surface during $16 \mathrm{hrs}$. are $56.25 \%$ and $42.5 \%$, respectively.
\end{abstract}

\section{Introduction}

Thermal energy storage (TES) plays a significant role in energy conservation and the development of renewable resources. This kind of storage can help to resolve the mismatch between energy supply and demand as well as boost the dependability of the energy production systems. Among different types of thermal energy storage, latent heat thermal energy storage (LHTES) using phase change materials (PCM) as a storage medium is the most effective due to its high storage density with small temperature variation [1]. PCM is used in several engineering applications, such as domestic hot water, heating and cooling systems, building air-conditioners, electronic devices cooling, drying technology, solar cookers, preservation of food and pharmaceutical products [2]. More recently, the shell-and-tube LHTES system has received the greatest research attention due to its design simplicity and high efficiency. However, the evolution of LHTES systems faces great challenges due to the low thermal conductivity of phase change materials, which leads to a low heat transfer rate during melting and solidification processes [3]. Many numerical and experimental studies have been done over the years to enhance the rate of heat transmission between the heat exchanger surface and the PCM. Furthermore, various 
research has been carried out thus far on the importance of optimizing the system configuration for the shell-andtube LHTES units. Wang et al. [4] presented a numerical investigation to study the influences of the mass flow rate of HTF and temperature variation between the inlet of water and fusion point of PCM on the melting and solidification behaviors in axis-symmetric of shell and tube LHTES system. It is observed that the water inlet temperature displayed higher impact on the total time to complete melting and solidification operations. Also, the increase in the water entry temperature leads to increase the storage of heat as the non-linear shape. Mahdi et al. [5] numerically studied the melting and solidification performance of a PCM (paraffin wax RT-50) location in a double-pipe heat exchanger where in the first model they used the shell side for PCM and the tube for heat transfer fluid (HTF), whereas they used the opposite in the second model. Their results indicated that the charging time for a second model decreased by up to $50 \%$ when compared with the first model due to the high influence of convection. Jasim et al. [6] performed a numerical study on nanoparticles and fins to enhanced solidification of PCM inside heat exchanger. Their results reveal that fins alone produce greater performance than nanoparticles alone or a mix of fins and nanoparticles. Al-Siyabi et al. [7] conducted an experimental and numerical investigation into the effect of slope angle $\left(0^{\circ}, 45^{\circ}\right.$, and $\left.90^{\circ}\right)$ on the thermal behavior of PCM in a vertical cylindrical storage unit. It was observed that to produce the fastest melting rate, the slop angle should be around $45^{\circ}$. The slope angle of $0^{\circ}$ has quicker melted PCM in the axial orientation, while the opposite was seen at slope angle $90^{\circ}$, where PCM melts faster in the radial orientation. Shen et al. [8] numerically studied the influence of the radius ratio in a vertical storage unit under two different chains: constant tube radius with changing shell radius and change tube radius with constant shell radius. They found that the ideal radius ratio a little rise when the total melting/solidification time increases. Also, the best shell-to-tube radius ratio is around five for both chains. The focus of this study is to evaluate natural convection effects during melting of paraffin wax in double pipe heat exchange systems.

Avci and Yazici [4] presented an experimental investigation to study the thermal behavior of PCM in a horizontal shell and tube heat exchanger. The findings revealed that natural convection is effective for heat transmission for solidification performance at first, followed by conduction. At a melting process, however, the opposite occurs. Jesumathy et al. [5] experimentally investigated the melting and solidification characteristics of a PCM in the annulus of two concentric horizontal cylinders. Their results indicated that natural convection, as a result of buoyancy factors, governs the charging process, whereas the discharging process is controlled by conduction. Rathod and Banerjee [6] have conducted an experimental investigation to evaluate the LHTES system performance of a double pipe heat exchanger. They found that during the charging cycle, free convection is the domain of heat transport in the Paraffin wax. Moreover, thermal conduction controls the discharge cycle. Yazici et al [7] carried out an experimental study to determine the impression of solidification behavior in horizontal shell and tube storage units by switching from concentric to eccentric geometries. It was observed that the solidification time was high when adopting eccentric geometries. Hosseini et al [8] experimentally and numerically investigated the influence of the inlet temperature of HTF and the thermal behavior of the PCM during melting and solidification in the shell-and tube LHTES unit. Their results showed that raising the inlet water temperature to $80{ }^{\circ} \mathrm{C}$ leads to reduces melting times of the phase change material by $37 \%$. Also, theoretical efficiency of the shell and tube storage system in melting and solidification cycles grew from $81.1 \%$ to $88.4 \%$. Longeon et al [9] carried out an experimental and numerical simulation to study the PCM influence on melting and solidification operations in a vertical double pipe energy storage system. The study was conducted in the two cases, feeding HTF upper and lower in charging also repeated in discharging. Obtained results showed that the PCM placed in the top parts heated up quicker and had higher gradients as a result of their proximity to the injection. They noticed that the values were very close during the charging process due to the effect of free convection. Furthermore, the opposite occurs during the discharge process. Kibria et al [10] presented an experimental and numerical investigation of heat transfer and the effects of PCM on the thermal latent heat energy storage system, which was governed by thermal conduction. They observed that the tube radius produced heat transfer rates between HTF and PCM that were greater than the thickness parameters. The results indicate that the temperature of the inlet HTF has significant influence on the improvement of the performance of the PCM storage unit. Mahdi et al. [11] have conducted a numerical investigation to study the influence of the phase change material location during the charging and discharging cycles on the thermal behaviour of the LHTES unit in horizontal shell-and-tube heat exchanger type by using two different models. The first model was the paraffin wax RT 50 filling shell as PCM while the water as heat transfer fluid flows through the tube. The second model was the paraffin wax filling tube as PCM while the water as heat transfer fluid flows through the shell. They 
found that the charging time for a second model decreased which was caused by high impact of convection up to $50 \%$ when compared with that of the first model.

The main feature of this study is the detailed simulation of the temperature field within the PCM moreover to liquid fraction values in the domain. In this work, the objective of the present study is to evaluate and analyze of PCM discharging process in the annulus geometry of a double-pipe heat exchanger. Where the history of the thermal behavior of PCM during the solidification process investigated. The results will be more important in many engineering applications especially of thermal storage applications in the heat exchanger and PCM material properties behavior during these applications.

\section{Mathematical Model}

\subsection{Physical Model Descriptions}

Figure (1) shows the schematic geometry case study of shell-and-tube LHTES system, which consists of two concentric tubes. The tube is made of copper and has an inner diameter of $51 \mathrm{~mm}$ and an outer diameter of $54 \mathrm{~mm}$, while the shell is composed of aluminium and has an inner diameter of $157 \mathrm{~mm}$ and an outer diameter of $160 \mathrm{~mm}$. The annulus is filled with paraffin wax as PCM while water as HTF flows through the inner tube. On the other hand, thermo-physical properties of PCM, water, aluminium and copper that utilized in the numerical study is shown in Table (1). To simplify the numerical model, the following assumptions are made:

$>$ The flow is laminar, incompressible, Newtonian fluid and two-dimensional.

$>$ The PCM is homogeneous and isotropic.

$>$ The viscous dissipation is negligible.

$>$ The inlet temperature of HTF is constant at $300 \mathrm{~K}$.

$>$ The Boussinesq approximation is implemented to density and buoyant force.

$>$ The outer surface of the shell is insulated.

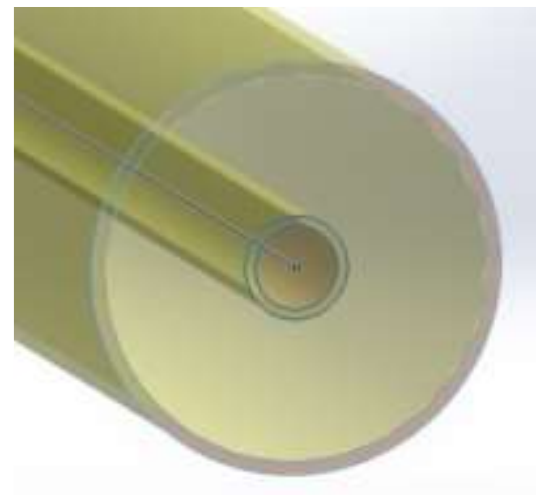

(a)

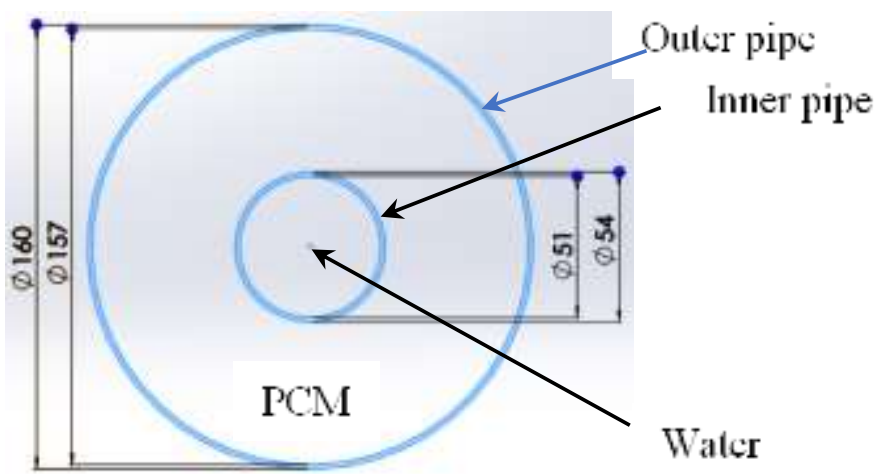

(b)

Figure (1). Schematic diagram of concentric annulus pipes (dimensions in mm), (a) 3D view of concentric annulus, and (b) Cross section views of concentric annulus.

\subsection{Governing Equations}

Enthalpy -porosity method is used $[12,13,14,15]$ to simulate the solidification process of the PCM due to its ability resolve explicit tracking of the solid-liquid interface position as well as ease to solve issues related to the phase change [16]. This method affords the exact simulation results and the best image of the required operations. The advantages of this technique method are as following:

Multi-dimensions, Numerical solution.

$>$ It is update and more accurate.

$>$ The enthalpy components at a mushy zone contain a mixture of each solid/liquid material.

$>$ The governing equations are alike to the single-phase equation.

$>$ There is no explicit requirement for the solid/liquid interface.

$>$ All researchers depend on it now $[12,13,14,15]$. 
Numerical models were used to simulate the cases of the present study, passing through four steps which are:

Modeling the required geometry.

$>$ The mesh generation.

$>$ Insert the governing equations, materials, cell zone conditions, boundary conditions, solution method, and control.

$>$ Analysis of the results and post-processing.

The continuity, momentum and energy equations can be written as:

Continuity equation:

$\frac{\partial \rho}{\partial t}+\nabla \cdot(\rho v)=0$

Momentum equation:

$\frac{\partial \rho v}{\partial t}+\nabla \cdot(\rho v v)=-\nabla P+\nabla \cdot(\mu \nabla v)+\rho g+\frac{(1-f)^{2}}{f^{3}+\varepsilon} v A_{m u s h}$

Energy equation:

$\frac{\partial \rho H}{\partial t}+\nabla \cdot(\rho v H)=\nabla \cdot(k \nabla T)+S$

The enthalpy is calculated as the sum of sensible enthalpy $\mathrm{h}$ and latent heat $\Delta H$ given by follows:

$\boldsymbol{H}=\boldsymbol{h}+\Delta \boldsymbol{H}$

$h=h_{r e f}+\int_{T_{r e f}}^{T} C_{P} d T$

$\Delta \boldsymbol{H}=\boldsymbol{f} \boldsymbol{L}$

where: liquid fraction $f$ can be defined as:

$$
f=\left\{\begin{array}{c}
0 \\
\frac{T-T_{\text {Solidus }}}{T_{\text {Liquidus }}-T_{\text {Solidus }}} \\
\mathbf{1}
\end{array}\right\} \begin{gathered}
T<T_{\text {Solidus }} \\
T_{\text {Solidus }} \leq T \leq T_{\text {Liqudus }} \\
T>T_{\text {Liquidus }}
\end{gathered}
$$

Rearranging the energy equation by applying equations (4), (5), (6) and (7) into eq. (3) gives:

$\frac{\partial \rho h}{\partial t}+\nabla \cdot(\rho v h)=\nabla \cdot(k \nabla T)-\frac{\partial \rho f L}{\partial t}-\nabla \cdot(\rho v f L)+S$

The density variation is defined as:

$\rho=\rho_{0}\left(1-\beta\left(T-T_{0}\right)\right)$

The Boussinesq approximation $[17,18,19]$ is used to take into consideration the free convection within the PCM region. By substituting eq. (9) in eq. (2), the momentum equation can be written as:

$\frac{\partial \rho_{0} v}{\partial t}+\nabla \cdot(\rho v v)=-\nabla P+\nabla \cdot(\mu \nabla v)+\left(\rho-\rho_{0}\right) g+\frac{(1-f)^{2}}{f^{3}+\varepsilon} v A_{m u s h}$ 
The term $A_{\text {mush }}$ is the mushy zone constant which works as a factor steeply the velocity is reduced to zero when the PCM solidifies and the value in this study is $10^{5}$.the constant $\varepsilon$ is a tiny number $(0.001)$ to prevent division by zero. $\rho_{0} \& T_{0}$ are the operating density and temperature, $\beta$ is thermal expansion coefficient, $g$ is the gravitational acceleration, $\mathrm{P}$ is the pressure and $\mu$ is dynamic viscosity.

Table (1). Thermo-physical properties [20].

\begin{tabular}{|c|c|c|c|c|}
\hline Property & PCM & Water & Aluminum & Copper \\
\hline Melting temperature $[\mathrm{K}]$ & 334 & & & \\
\hline Density in solid state $\left[\mathrm{kg} / \mathrm{m}^{3}\right]$ & 894.56 & & 2719 & 8978 \\
\hline Density in liquid state $\left[\mathrm{kg} / \mathrm{m}^{3}\right]$ & 783.42 & 998.2 & & \\
\hline Specific heat in solid state $[\mathrm{J} / \mathrm{kg} \mathrm{K}]$ & 1659 & & 871 & 381 \\
\hline Specific heat in liquid state $[\mathrm{J} / \mathrm{kg} \mathrm{K}]$ & 2460 & 4182 & & \\
\hline Latent heat of fusion $[\mathrm{J} / \mathrm{kg}]$ & 235512.5 & & & \\
\hline Thermal conductivity in solid state $[\mathrm{W} / \mathrm{mK}]$ & 0.259 & & 202.4 & 387.6 \\
\hline Thermal conductivity in liquid state [W/mK] & 0.158 & 0.6 & & \\
\hline Dynamic viscosity $[\mathrm{kg} / \mathrm{m} \mathrm{s}]$ & 0.01405 & 0.001003 & & \\
\hline Solidus temperature $[\mathrm{K}]$ & 318.5 & & & \\
\hline Liquidus temperature $[\mathrm{K}]$ & 339 & & & \\
\hline Thermal expansion coefficient $[1 / \mathrm{K}]$ & 0.000307 & & & \\
\hline Density $\left[\mathrm{kg} / \mathrm{m}^{3}\right]$ & $2621.3-5.4215 \mathrm{~T}$ & & & \\
\hline Specific heat capacity $[\mathrm{kJ} / \mathrm{kg} . \mathrm{K}]$ & $-10786+39.073 \mathrm{~T}$ & & & \\
\hline Thermal conductivity $[\mathrm{W} / \mathrm{m} . \mathrm{K}]$ & $1.8282-0.0049268 \mathrm{~T}$ & & & \\
\hline
\end{tabular}

\subsection{Boundary and Initial Conditions}

Due to of symmetry case, the solution domain is selected as the right-half of the annulus. At time $=0$, the PCM was in a liquid state, so its temperature was $67^{\circ} \mathrm{C}$. the $\mathrm{HTF}$ has a constant temperature $\left(T_{f}=27^{\circ} \mathrm{C}\right)$, which is lower than the PCM solidification temperature and therefore, the initial temperature of the entire system is set to $\mathrm{Ti}=67^{\circ} \mathrm{C}$, near to the melting point, while the side surface of the outer tube is insulated .The inner tube was where HTF inside assumes that the inner tube surface is at the same temperature as the water, $25{ }^{\circ} \mathrm{C}$ (isothermal) according to the low Reynolds number in this case study and to simplify our case from three dimensions to two dimensions. Moreover, to investigate the influence of natural convection on the solidification process. The boundary conditions are presented as shown in Figure (2).

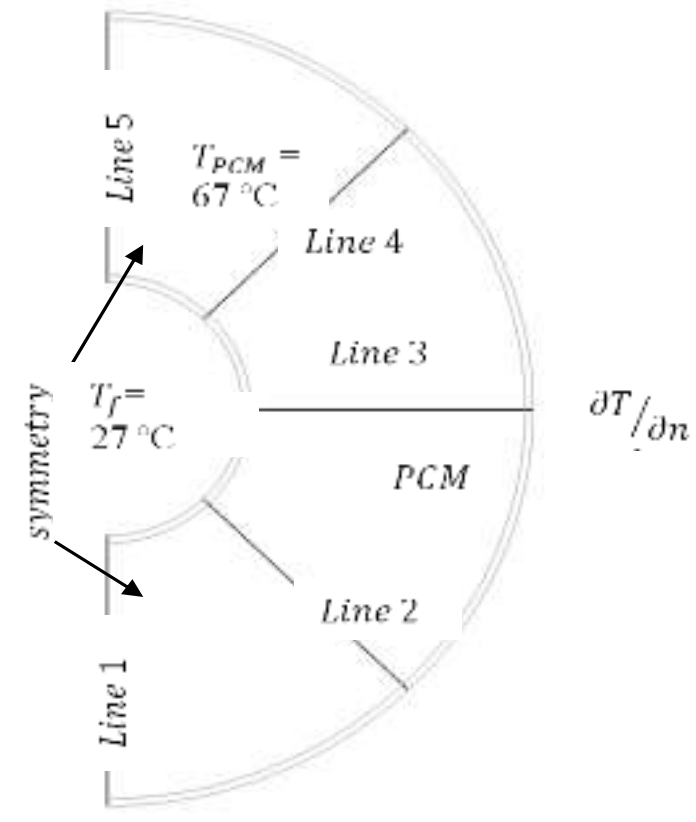

Figure (2). Boundary conditions of the domain. 


\subsection{Numerical Procedure and Mesh Dependency}

The numerical solution of the transient two-dimensional problem was executed utilizing the finite volume method. The current problem is solved numerically utilizing the CFD program, FLUENT 20. The pressurevelocity coupling equations were solved with the Semi-Implicit Pressure-Linked Equation (SIMPLE) algorithm and the pressure correction equation was solved with the PRESTO scheme. A QUICK differencing scheme is used to discretize the momentum and energy equations. Tables $(2 \& 3)$ show the grid sizes studied to validate the numerical solution for grid size independence. Figure (3) depicts the structure mesh that was employed in this study (315601). The time step is set to $0.01 \mathrm{~s}$ and each time step has a number of 300 . At each time step, with a convergence criterion of $10^{-6}$ for all variables. Mesh dependency applied to present case study during transient solution after 3 hours according to PCM average temperature PCM liquid fraction.

Table (2). Mesh dependency in the present study for PCM average temperature after 3 hours of solidification process.

\begin{tabular}{|l|r|r|r|r|r|r|} 
No. of nodes & 256478 & 290865 & 312323 & 315601 & 326145 & 358213 \\
\hline Line 1 & 26.31482 & 37.5926 & 41.76956 & 42.622 & 42.83511 & 42.40676 \\
\hline Line 2 & 30.35262 & 43.36088 & 48.17876 & 49.162 & 49.40781 & 48.91373 \\
\hline Line 3 & 32.69195 & 46.70278 & 51.89198 & 52.951 & 53.21576 & 52.6836 \\
\hline Line 4 & 35.22267 & 50.3181 & 55.909 & 57.05 & 57.33525 & 56.7619 \\
\hline Line 5 & 36.11852 & 51.59788 & 57.33098 & 58.501 & 58.79351 & 58.20557 \\
\hline
\end{tabular}

Table (3). Mesh dependency in the present study for PCM liquid fraction after 3 hours of solidification process.

\begin{tabular}{|c|c|c|c|c|c|c|}
\hline No. of nodes & 256478 & 290865 & 312323 & 315601 & 326145 & 358213 \\
\hline Line 1 & 0.158208 & 0.226012 & 0.251124 & 0.279027 & 0.279585 & 0.279306 \\
\hline Line 2 & 0.158208 & 0.226012 & 0.251124 & 0.279027 & 0.279585 & 0.279306 \\
\hline Line 3 & 0.237691 & 0.339558 & 0.377287 & 0.419208 & 0.420046 & 0.419627 \\
\hline Line 4 & 0.341567 & 0.487953 & 0.54217 & 0.602411 & 0.603616 & 0.603013 \\
\hline Line 5 & 0.378334 & 0.540477 & 0.60053 & 0.667255 & 0.66859 & 0.667922 \\
\hline
\end{tabular}

\subsection{Model Validation}

The reliability of the simulation was validated by comparing the current numerical forecasts to prior findings as a [2] and [21] under the same conditions. Figure (4) depicts the validation result. It can be observed that the predicted transient PCM temperatures in good accordance with the other results. The validation results demonstrate that the current physical model and simulation are correct and dependable. The physical configuration of the validation case study, the inner tube radius is $25.4 \mathrm{~mm}$ with $1.2 \mathrm{~mm}$ thickness, the middle tube radius is $75 \mathrm{~mm}$ and the outer tube radius is $100 \mathrm{~mm}$; with $2 \mathrm{~mm}$ thickness, all pipes are made from copper to ensure high thermal conductivity and to enhance heat transfer between the PCM and the heat transfer fluid [2].

The minimum temperature required to operate the liquid desiccant air conditioning was approximately $65{ }^{\circ} \mathrm{C}$. Water was used as fluid because of its high heat capacity and low cost, so the maximum charging temperature was $95{ }^{\circ} \mathrm{C}$ which equivalent to $13{ }^{\circ} \mathrm{C}$ temperature difference between the PCM and the heat transfer fluid. For more details about validation case can be found in [2]. Finally, the validation case finds a good agreement the previous studies according the average error about $4.5 \%$ and $3.3 \%$ with [2] and [21] respectively. 


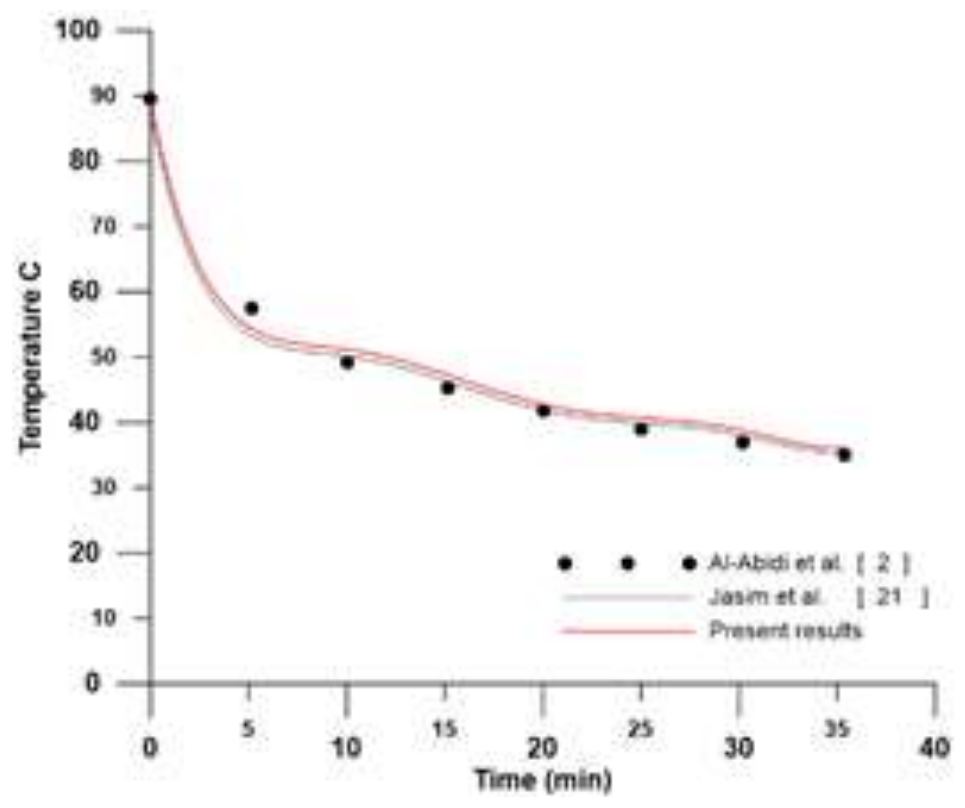

Figure (4). Comparison of temperature profile vs. previous studies Al-Abidi et al. [2] and Jasim et al [21].

\section{Results and Discussion}

In order to evaluate the thermal performance of PCM in a horizontal shell-and-tube LHTES system during the solidification operation, low-temperature HTF is passed through the inner tube to remove thermal energy from high-temperature liquid PCM in the annulus. The temperature of the PCM $\left(67^{\circ} \mathrm{C}\right)$ was higher than the melting point. Whereas, the cold HTF has a temperature of $27^{\circ} \mathrm{C}$. Figure (5) presents the temperature contours of the PCM at different time steps from $0 \mathrm{~s}$ to $59575 \mathrm{~s}$ during the solidification process. At the initial time $\mathrm{t}=0 \mathrm{~s}$, the liquid fraction value is one, indicating that the state is liquid. Due to the hugely large temperature difference between liquid PCM and the HTF, the sensible heat of the PCM is removed by natural convection in the liquid PCM. As a result, the temperature of the PCM rapidly drops to the freezing point. When that, the PCM that surrounded the tube began to solidify, forming a solid PCM layer around the tube. It can be seen that the liquid of PCM decreases with the increasing thickness of the solid layer. The reason is that thermal resistance increases with the increase in the thickness of the solid layer, leading to the heat exchange rate reducing. Consequently, the decreased rate of heat transfer led to reduction in a decrease in the rate of PCM phase change from liquid to solid. This indicates that thermal conduction between the HTF and the solid/ liquid interface controls the rate of solidification.

The liquid fraction decreases gradually with time, convection circulation occurs in the liquid area of PCM, causing a clockwise and anti-clockwise vortex to form to the left and right of the tube, respectively. The hightemperature liquid PCM flows upward due to natural convection, whereas the low-temperature liquid PCM flows downward due to gravity. On the other hand, effects of buoyancy and convective heat transfer can explain why the lower part of the PCM solidifies faster than the upper part. Thermal conduction dominates heat transport, giving for adequate time for slow solidification It takes approximately 16 hours for the PCM temperature to drop from $340 \mathrm{~K}$ to $302 \mathrm{~K}$ during a discharging process. The same behavior repeated in Figure (6) according to liquid fraction value. It is noted that the solid phenomena found on the bottom side of the annulus are due to the buoyancy force effect. Especially after $990 \mathrm{~s}$ until reaching a solid state after $5957 \mathrm{~s}$. 


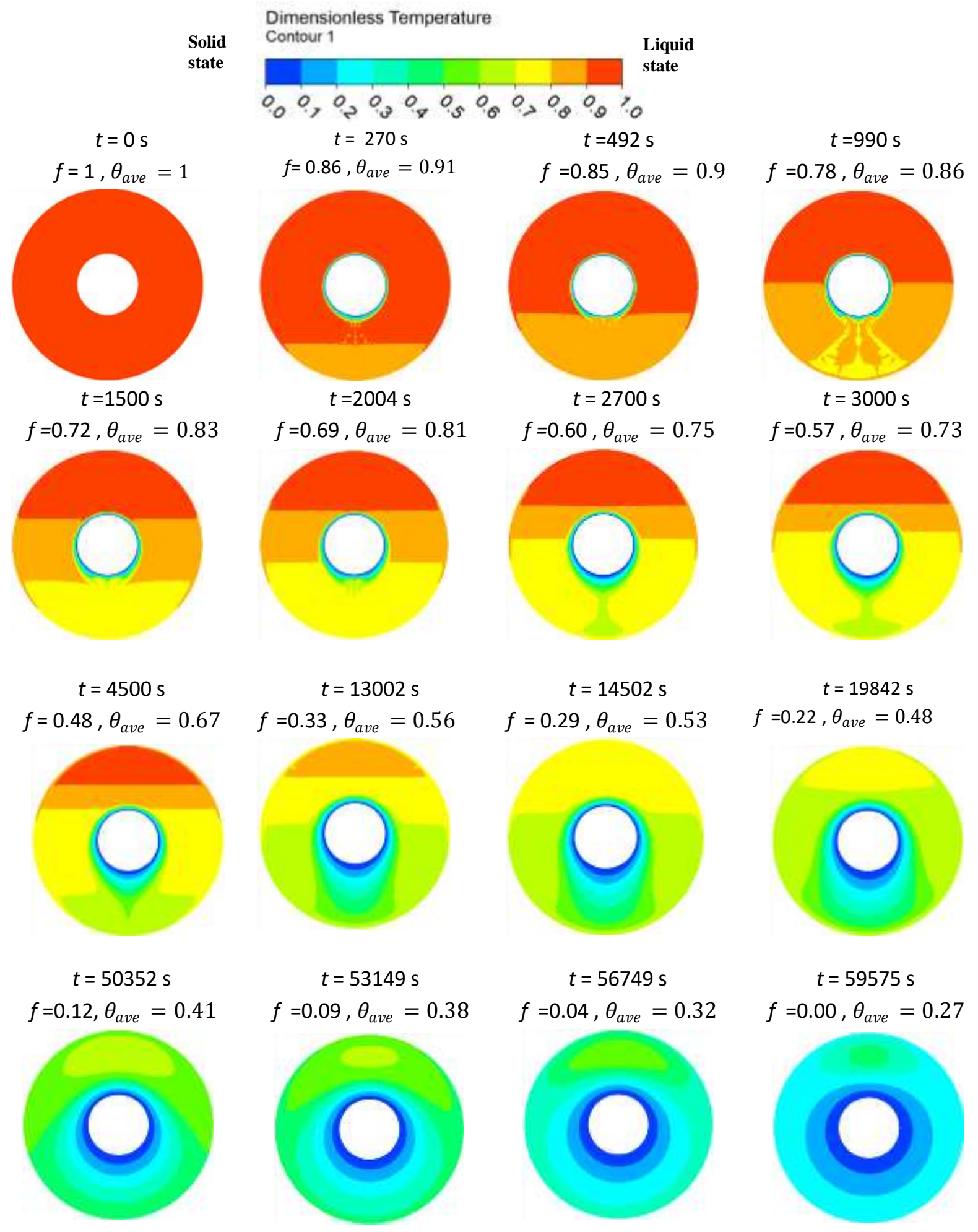

Figure (5). Contours of PCM transient temperature during discharging process. 

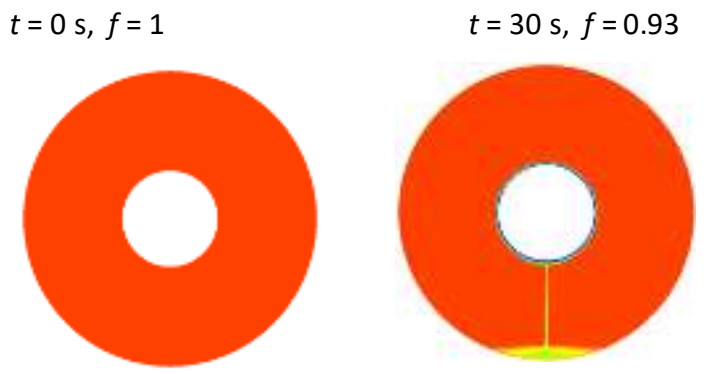

$t=492 \mathrm{~s}, f=0.85$

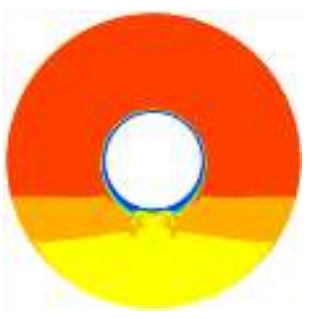

$t=4500 \mathrm{~s}, f=0.48$

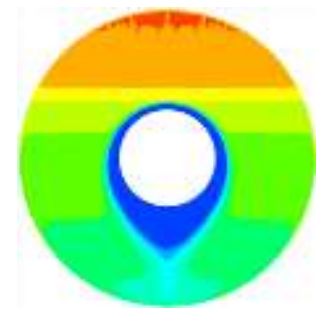

$t=50352 \mathrm{~s}, f=0.12$

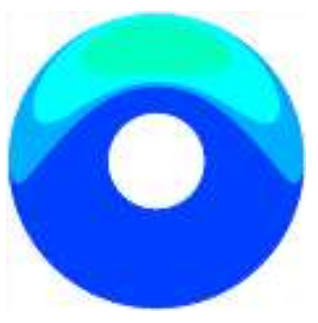

$t=990 \mathrm{~s}, f=0.78$

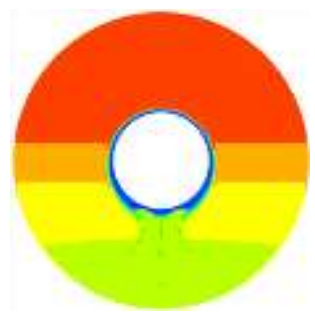

$t=6504 \mathrm{~s}, f=0.43$

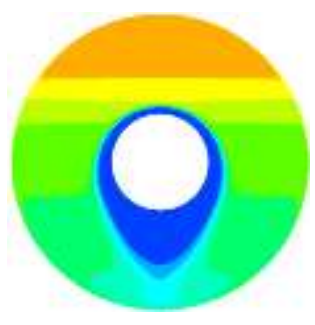

$t=53149 \mathrm{~s}, f=0.09$

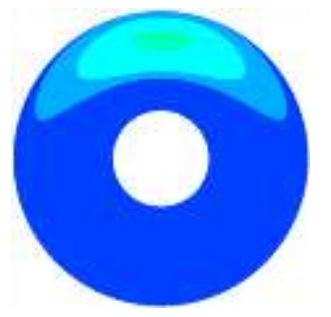

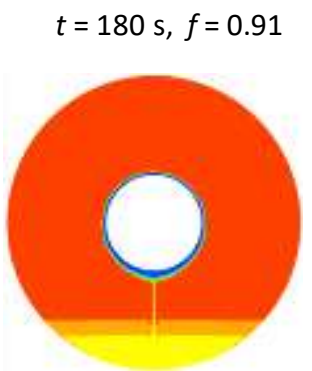

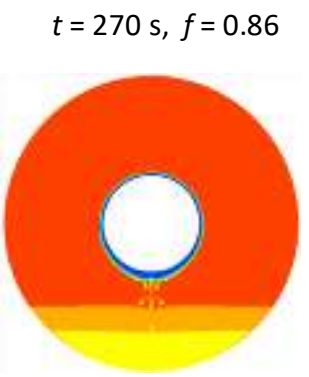

$t=2004 \mathrm{~s}, f=0.69$

$t=3000 \mathrm{~s}, f=0.57$
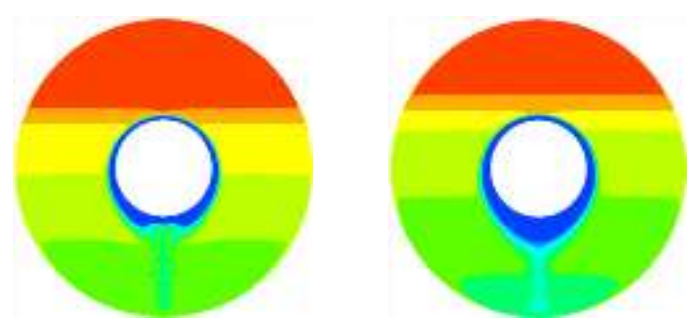

$t=13002 \mathrm{~s}, f=0.33$

$t=19842 \mathrm{~s}, f=0.22$
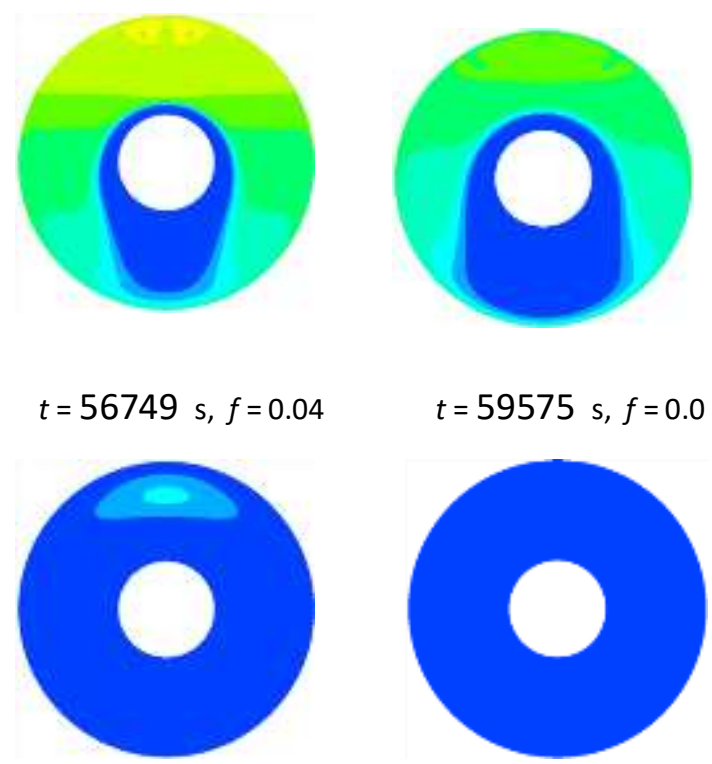

Figure (6). Contours of the PCM transient liquid fraction during discharging process.

Figure (7) shows the temperature distribution on the annulus radius in dimensionless form for different times and locations in the domain. Whereas at the beginning, the max. Temperature did not exceed $55^{\circ} \mathrm{C}$ at line 1 , after that the time increase led to a decrease the temperature profile along line 1, where the solid state would dominate. But this distribution is irregular and depends on buoyancy force effects. Finally, after 16 hours, the maximum temperature reached $37^{\circ} \mathrm{C}$. This drops in max. Temperature along line 1 by $32 \%$ during this time period. The temperature gradient was small at the beginning, but it became strong as time increased, especially near the outer pipe surface. On the other hand, the temperature gradient is constant nearly from $\dot{R} R=0.25$ to the end of $\dot{R} R=1$ when time equals 3 hours (line 3 ), but after that the temperature gradient quickly becomes irregular due to solids phenomena. This behavior is repeated along other lines, but it is strong and quick. 

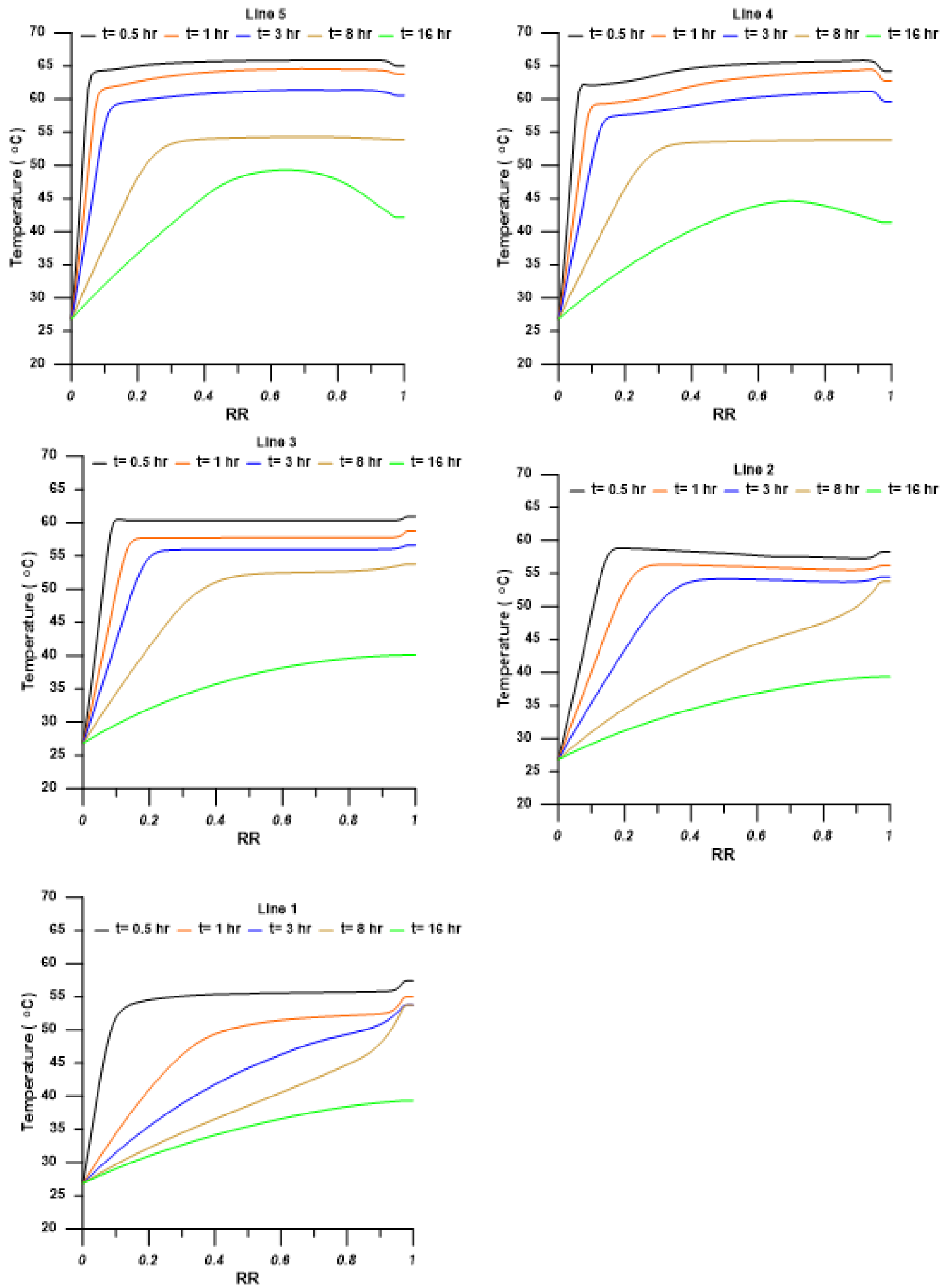

Figure (7). Temperature with dimensionless radius for different times and locations in the annulus. 
Figure (8) presents the PCM transient liquid fraction contours during the discharging process, where the decrease from 1 at time $=0$ to 0 at time $=59575 \mathrm{~s}$. The temperature changes near the outer pipe surface during 16 hrs. can be seen in Table (4), while the liquid fraction changed during $16 \mathrm{hrs}$ as Table (5) according to Figures (7 \& 8) as shown below. According to Table (4) the temperature difference has lower value at line 1 while it is increase to higher value at line 5 due to line location in the dolman and bouncy force direction with or without gravity force. Table (5) presents the solid-state domain according to $\dot{R} R$ value in the annulus. Where $\dot{R} R$ near the zero leads that to the location near the inner tube surface where it is near to the HTF while when $\dot{R R}$ close to 1 that means neared to the outer tube surface. From the table the liquid fraction changes from lower value at starting time and it is increase gradually with time to reach 1 in the end of scarification processes approximately about $16 \mathrm{hr}$. In line 2 there is a fluctuation values of the liquid fraction values due to turbulence effects and bouncy force movement in this case.

Table (4). Temperature changes near the outer pipe surface during $16 \mathrm{hrs}$.

\begin{tabular}{|c|c|c|}
\hline$\Delta T_{\max .}=T_{h}-T_{c}$ & $\Delta T=T-T_{c}$ & Percentage $=\Delta T / \Delta T_{\max }$ \\
\hline Line 1 & $17^{\circ} \mathrm{C}$ & $\varepsilon r, 0 \%$ \\
\hline Line 2 & $18^{\circ} \mathrm{C}$ & $\{0 \%$ \\
\hline Line 3 & $20^{\circ} \mathrm{C}$ & $0 . \%$ \\
\hline Line 4 & $21.8^{\circ} \mathrm{C}$ & $0 \leqslant, 0 \%$ \\
\hline Line 5 & $22.5^{\circ} \mathrm{C}$ & $07, Y 0 \%$ \\
\hline
\end{tabular}

Table (5). Liquid fraction changes in the annulus during $16 \mathrm{hrs}$. according to $\dot{R} R$ value.

\begin{tabular}{|c|c|c|c|c|c|}
\hline \multicolumn{7}{|c}{$\dot{R} R$ where $\dot{R} R=0$ at time $=0$} \\
\hline Time (hr.) & 0.5 & 1 & 3 & 8 & 16 \\
\hline Line 1 & 0.05 & 0.28 & 0.56 & 0.82 & 1 \\
\hline Line 2 & 0.025 & 0.14 & 0.23 & 0.68 & 0.98 \\
\hline Line 3 & 0.04 & 0.09 & 0.12 & 0.28 & 0.96 \\
\hline Line 4 & 0.025 & 0.05 & 0.08 & 0.18 & 0.94 \\
\hline Line 5 & 0.02 & 0.04 & 0.06 & 0.175 & 0.55 \\
\hline
\end{tabular}



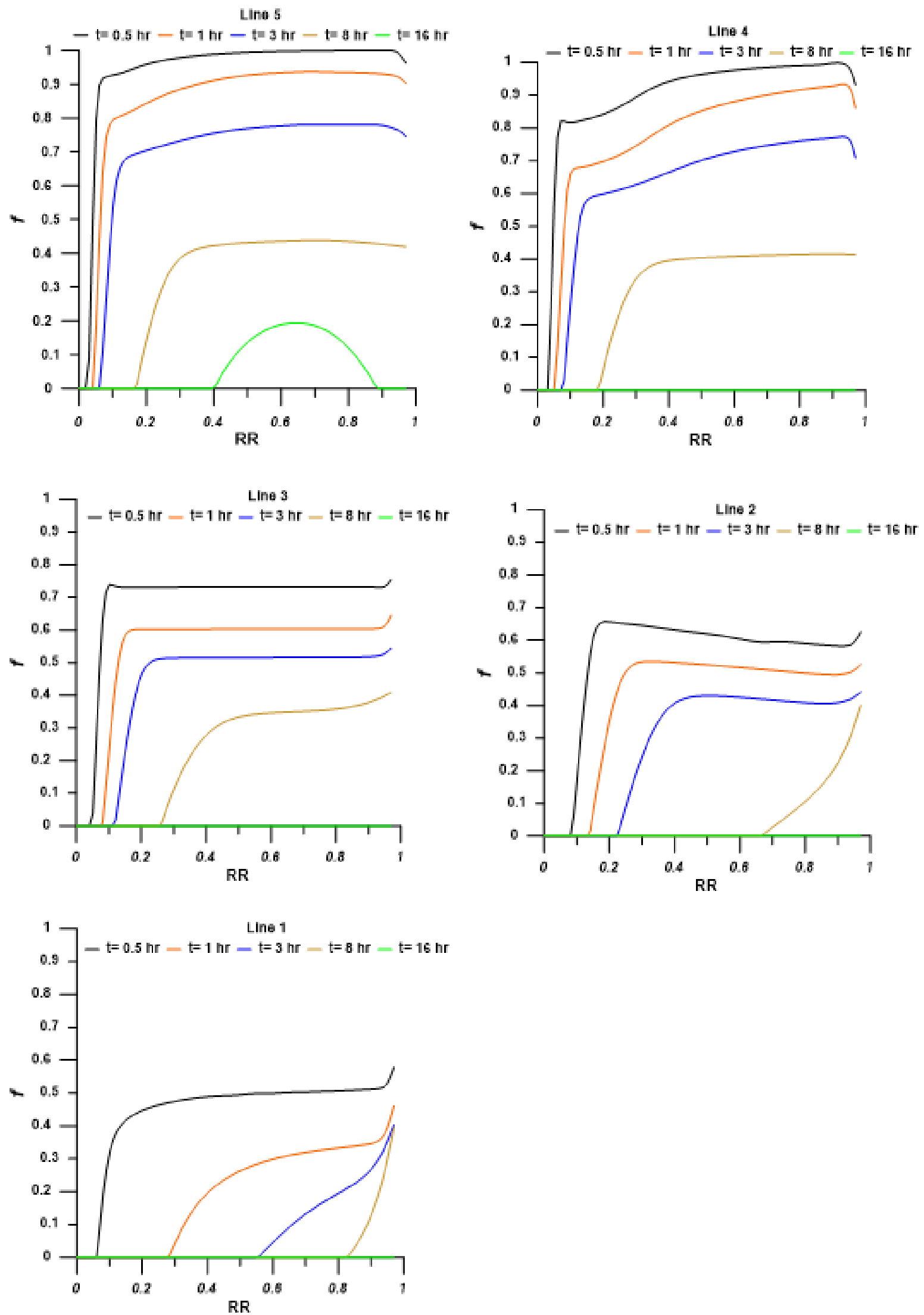

Figure (8). Liquid fraction with dimensionless radius for different times and locations in the annulus. 


\section{Conclusions}

In the present study, an annulus model was established to investigate the PCM solidification process in the shell and tube geometry. Natural convection plays a role only during the early periods of solidification. Conduction remains the dominant heat transfer mode for the entire process. In the plain tube circumstance, the predicted result shows the capturing phenomenon: primary heat conduction in all regions, then heat convection and conduction become dominant in the top and bottom regions, respectively. The max. and min. temperature changes near the outer pipe surface during $16 \mathrm{hrs}$. are $56.25 \%$ and $42.5 \%$, respectively. The findings of the visualization study are confirmed by the numerical results that show strong thermal stratification of the solidification process in the upper part of the tube.

Acknowledgements: The authors would like to acknowledge the contribution of the University Of Anbar (www.uoanabar.edu.iq) via their prestigious academic staff in supporting this research with all required technical and academic support.

$\begin{array}{ll}\text { Nomenclature } \\ \mathrm{A} & \text { Mushy zone constant }\left(\mathrm{kg} / \mathrm{m}^{3} \cdot \mathrm{s}\right) \\ C_{P} & \text { Specific heat }(\mathrm{J} / \mathrm{kg} \cdot \mathrm{K}) \\ \mathrm{f} & \text { Liquid fraction } \\ \mathrm{g} & \text { Gravitational acceleration }\left(\mathrm{m} / \mathrm{s}^{2}\right) \\ \mathrm{h} & \text { Sensible enthalpy }(\mathrm{J} / \mathrm{kg}) \\ \mathrm{H} & \text { Total enthalpy }(\mathrm{J} / \mathrm{kg}) \\ \mathrm{k} & \text { Thermal conductivity }\left(\mathrm{W} / \mathrm{m}^{2} \mathrm{~K}\right) \\ \mathrm{L} & \text { Latent heat }(\mathrm{J} / \mathrm{kg}) \\ \dot{R} R & \text { Dimensionless annulus radius } \\ \mathrm{P} & \text { Pressure }(\mathrm{Pa}) \\ \mathrm{S} & \text { Source term } \\ \mathrm{t} & \text { Time }(\mathrm{s}) \\ \mathrm{T} & \text { Temperature }(\mathrm{K}) \\ \mathrm{V} & \text { Velocity }(\mathrm{m} / \mathrm{s}) \\ \Delta \mathrm{H} & \text { Latent enthalpy }(\mathrm{J} / \mathrm{kg})\end{array}$

$\begin{array}{ll}\begin{array}{l}\text { Greek } \\ \text { letter }\end{array} & \\ \rho & \text { Density }\left(\mathrm{kg} / \mathrm{m}^{3}\right) \\ \mu & \text { Dynamic viscosity }(\mathrm{kg} / \mathrm{m} \cdot \mathrm{s}) \\ \varepsilon & \text { Small number } \\ \beta & \text { Volumetric expansion coefficient }(1 / \mathrm{K}) \\ \text { Subscripts } & \\ \text { HTF } & \text { Heat transfer fluid } \\ \text { Mush } & \text { Mushy zone } \\ \text { Ref. } & \text { Reference } \\ \text { i } & \text { Initial state } \\ \text { Solidus } & \text { Solid phase } \\ \text { Liquidus } & \text { Liquid phase }\end{array}$

\section{References}

[1] G. S. Han, H. S. Ding, Y. Huang, L. G. Tong, Y. L. Ding, "A comparative study on the performances of different shell-and-tube type latent heat thermal energy storage units including the effects of natural convection," International Communications in Heat and Mass Transfer, vol. 88, pp. 228-35, 2017.

[2] A. A. Al-Abidi, S. Mat, K. Sopian, M. Y. Sulaiman, A. T. Mohammad, "Numerical study of PCM solidification in a triplex tube heat exchanger with internal and external fins," International Journal of Heat and Mass Transfer, vol. 61, pp. 684-95, 2013.

[3] S. Seddegh, X. Wang, A. D. Henderson, "Numerical investigation of heat transfer mechanism in a vertical shell and tube latent heat energy storage system," Applied thermal engineering, vol. 87, pp. 698-706, 2015.

[4] M. Avci, and M. Y. Yazici, "Experimental study of thermal energy storage characteristics of a paraffin in a horizontal tube-in-shell storage unit," Energy conversion and management, vol. 73, pp. 271-277, 2013.

[5] S. P. Jesumathy, M. U. dayakumar, S. Suresh, S. Jegadheeswaran "An experimental study on heat transfer characteristics of paraffin wax in horizontal double pipe heat latent heat storage unit," Journal of the Taiwan Institute of Chemical Engineers, vol. 45, no. 4, pp. 1298-1306, 2014.

[6] M. K. Rathod, and J. Banerjee, "Experimental investigations on latent heat storage unit using paraffin wax as phase change material," Experimental heat transfer, vol. 27, pp. 40-55, 2014.

[7] M. Y. Yazici, M. Avci, O. Aydin, M. Akgun, "On the effect of eccentricity of a horizontal tube-in-shell storage unit on solidification of a PCM," Applied Thermal Engineering., vol. 64, no. 1-2, pp. 1-9, 2014.

[8] M. J. Hosseini, M. Rahimi, R. Bahrampoury, "Experimental and Computational Evolution of a Shell and Tube Heat Exchanger as a PCM Thermal Storage System," International Communications in Heat and Mass Transfer, vol. 50, pp. 128-36, 2014. 
[9] M. A. S. Longeon, J. F. Fourmigué, A. Bruch, P. Marty, "Experimental and Numerical Study of Annular PCM Storage in the Presence of Natural Convection," Applied Energy, vol. 112, pp. 175-84, 2013.

[10] M. A. Kibria, M. R. Anisur, M. H. Mahfuz, R. Saidur, I. H. S. C. Metselaar, "Numerical and Experimental Investigation of Heat Transfer in a Shell and Tube Thermal Energy Storage System," International Communications in Heat and Mass Transfer, vol. 53, pp. 71- 78, 2014.

[11] M. S. Mahdi, H. B. Mahood, A. F. Hasan, A. A. Khadom, A. N. Campbell, "Numerical Study on the Effect of the Location of the Phase Change Material in a Concentric Double Pipe Latent Heat Thermal Energy Storage Unit," Thermal Science and Engineering Progress, vol. 11, pp. 40-49, 2019.

[12] R. B. Mahani, H. I. Mohammed, J. M. Mahdi, F. Alamshahi, M. Ghalambaz, P. Talebizadehsardari, W. Yaïci, "Phase change process in a zigzag plate latent heat storage system during melting and solidification," Molecules, vol. 20, pp. 4643, 2020.

[13] A. Elmeriah, D. Nehari, M. Aichouni, "hermo-convective study of a shell and tube thermal energy storage unit," Periodica Polytechnica Mechanical Engineering, vol. 62, no. 2, pp. 101-9, 2018.

[14] M. J. Hosseini, A. A. Ranjbar, K. Sedighi, M. Rahimi," A combined experimental and computational study on the melting behavior of a medium temperature phase change storage material inside shell and tube heat exchanger," International Communications in Heat and Mass Transfer, vol. 39, no. 9, pp. 1416-1424, 2012.

[15] M. M. Joybari, F. Haghighat, S. Seddegh, "Numerical investigation of a triplex tube heat exchanger with phase change material: Simultaneous charging and discharging," Energy and buildings, vol. 139, pp. 42638, 2017.

[16] S. Seddegh, X. Wang, A. D. Henderson, "A comparative study of thermal behaviour of a horizontal and vertical shell-and-tube energy storage using phase change materials," Applied Thermal Engineering, vol. 93, pp. 348-58, 2016.

[17] R. Ahmadi, M. J. Hosseini, A. A. Ranjbar, R. Bahrampoury, "Phase change in spiral coil heat storage systems," Sustainable cities and society, vol. 38, pp. 145-57, 2018.

[18] A. j. Parry, P. C. Eames, F. B. Agyenim, "Modelling of thermal energy storage shell-and-tube heat exchanger," Heat Transfer Engineering, vol. 35, no. 1, pp. 1-4, 2014.

[19] S. Seddegh, M. M. Joybari, X. Wang, F. Haghighat, "Experimental and numerical characterization of natural convection in a vertical shell-and-tube latent thermal energy storage system," Sustainable cities and society, vol. 35, pp. 13-24, 2017.

[20] A. N. Ghafoor, M. A. Mussa, "Numerical study of a thermal energy storage system with different shapes inner tubes," Journal of mechanics of continua and mathematical sciences, vol. 15, no. 4, pp. 21-35, 2020.

[21] Jasim M. Mahdi, Emmanuel C. Nsofora, "Solidification enhancement of PCM in a triplex-tube thermal energy storage system with nanoparticles and fins," Applied Energy, vol. 211, pp. 975-986, 2018. 